\title{
Humidification During Invasive Mechanical Ventilation: Less Lung Inflammation With Optimal Gas Conditioning
}

During normal breathing, the upper airway warms and moistens the inspired air such that, at the level of the main carina, humidity reaches $44 \mathrm{mg} \mathrm{H}_{2} \mathrm{O} / \mathrm{L}$ (100\% relative humidity at $37^{\circ} \mathrm{C}$, the average core temperature of humans). Conversely, during invasive mechanical ventilation, orotracheal or tracheostomy tubes bypass the upper airways, determining a decrease of approximately $75 \%$ of respiratory gas conditioning. ${ }^{1}$ As a result, at least some degree of artificial humidification is necessary inasmuch as it avoids mucociliary failure, epithelial damage, airway obstruction, and reduction in respiratory compliance. The optimal level of humidity and temperature, however, still remains to be determined. Some authors ${ }^{2,3}$ have suggested that normal values during spontaneous breathing should also apply to invasive mechanical ventilation. Likewise, based on experimental and clinical studies, the 2012 American Association for Respiratory Care guideline ${ }^{1}$ recommends a range of gas moisture between 33 and $44 \mathrm{mg}$ $\mathrm{H}_{2} \mathrm{O} / \mathrm{L}$ and temperature between 34 and $41^{\circ} \mathrm{C}$ with a relative humidity of $100 \%$. This range, however, has never been put to the test in terms of relevant outcomes, such as airway and lung inflammation.

In the current issue of RespiRATORY CARE, Jiang et $\mathrm{al}^{4}$ evaluated 5 different levels of gas conditioning in healthy rabbits under invasive mechanical ventilation. They assessed the effects of a wide range of absolute humidity on airway epithelium damage and on lung inflammation using cytokines in the bronchoalveolar lavage fluid, histologic lung injury score, and wet to dry ratio of the lungs. They found less lung inflammation and less epithelial damage in the group with more physiological gas conditioning, considering the core temperature of rabbits.

Mechanical ventilation is a supportive treatment and can be life-saving in many conditions. However, depend-

\footnotetext{
This work was supported by CAPES (Coordination for the Improvement of Higher Level Personnel). The authors have disclosed no conflicts of interest.

Correspondence: Mauro R Tucci MD PhD, Laboratório de Investigação Médica 09 (LIM-09), University of São Paulo School of Medicine, Av. Dr. Arnaldo, 455, $2^{\circ}$ andar, sala 2144, CEP 01246-903, São Paulo, SP, Brazil. E-mail: mrotucci@gmail.com.
}

DOI: $10.4187 /$ respcare. 04512 ing on the ventilator settings and on the underlying lung disorder, mechanical ventilation can in itself promote or perpetuate lung injury, a consequence known as ventilatorinduced lung injury. This injury is attributed to excessive stress (tension) and strain (deformation) of the lung cells,

See the Original Study on Page 1720

which express chemical signals (mechanotransduction) for the production of inflammatory cytokines and, depending on the intensity of these forces, cell damage or death. ${ }^{5,6}$ The findings of Jiang et $\mathrm{al}^{4}$ suggest that air conditioning, specifically temperature and absolute humidity, can also contribute to ventilator-induced lung injury. Of note, these findings suggest that experimental ventilator-induced lung injury studies have to be interpreted with caution, always taking into account the amount of humidification applied. This is particularly important since, in many of those studies, animals were ventilated without humidification at all. It is possible that some inconsistent results, mainly in animals with healthy lungs, ${ }^{7}$ could be reconciled by taking into account the degree of humidification.

It is interesting to speculate on the mechanism by which unfavorable air conditioning could lead to lung inflammation. It is well known that regions of damaged airway epithelium promote lung injury through production of mediators, such as pro-inflammatory cytokines, which participate in recruitment/activation of inflammatory cells, induction of alveolar cell death, and disruption of the alveolar capillary barrier. ${ }^{8}$ This mechanism is an important component of the physiopathology of ventilator-induced lung injury ${ }^{9}$ and of some airway diseases, such as COPD and asthma. ${ }^{10,11}$ In the case of air conditioning, it is possible that the trigger is the epithelium damage associated with low humidity, usually a few $\mathrm{mm}$ below the tip of the tracheal tube. ${ }^{12}$

The implications of these results for humans and clinical practice are not straightforward. First, the core temperature of rabbits is $1-2^{\circ} \mathrm{C}$ higher than for humans, so these studied temperature settings cannot be translated directly to humans. Second, lung inflammation was very mild, and it is not clear whether, with time, it would worsen enough to have an impact on clinical outcomes of patients. The results of clinical studies using less effective humidification devices ${ }^{13}$ suggest otherwise. However, avoidance 


\section{EDITORIALS}

of even mild degrees of inflammation can be relevant in the scenario of previously injured lungs, known to be more sensitive to second hits. In conclusion, no matter how appealing the concept of physiological air conditioning can be, it remains to be proven whether it improves the prognosis of ICU patients.

Mauro R Tucci MD PhD Respiratory ICU Pulmonary Division Heart Institute (Incor) Hospital das Clínicas University of São Paulo São Paulo, Brazil

Eduardo LV Costa MD PhD Respiratory ICU Pulmonary Division Heart Institute (Incor) Hospital das Clínicas University of São Paulo Research and Education Institute Hospital Siŕio-Libanês São Paulo, Brazil

\section{REFERENCES}

1. American Association for Respiratory Care, Restrepo RD, Walsh BK. Humidification during invasive and noninvasive mechanical ventilation: 2012. Respir Care 2012;57(5):782-788.

2. Williams R, Rankin N, Smith T, Galler D, Seakins P. Relationship between the humidity and temperature of inspired gas and the function of the airway mucosa. Crit Care Med 1996;24(11): 1920-1929.

3. Ryan SN, Rankin N, Meyer E, Williams R. Energy balance in the intubated human airway is an indicator of optimal gas conditioning. Crit Care Med 2002;30(2):355-361.

4. Jiang M, Song J, Guo X, Tang Y, Li H. Airway humidification reduces the inflammatory response during mechanical ventilation. Respir Care 2015;60(12):1720-1728.

5. Plataki M, Hubmayr RD. The physical basis of ventilator-induced lung injury. Expert Rev Respir Med 2010;4(3):373-385.

6. Gattinoni L, Carlesso E, Cadringher P, Valenza F, Vagginelli F, Chiumello D. Physical and biological triggers of ventilator-induced lung injury and its prevention. Eur Respir J Suppl 2003; 47:15s-25s.

7. Dreyfuss D, Ricard JD, Saumon G. On the physiologic and clinical relevance of lung-borne cytokines during ventilator-induced lung injury. Am J Respir Crit Care Med 2003;167(11):1467-1471.

8. Cheng DS, Han W, Chen SM, Sherrill TP, Chont M, Park GY, et al. Airway epithelium controls lung inflammation and injury through the NF- $\kappa$ B pathway. J Immunol 2007;178(10):6504-6513.

9. Manicone AM. Role of the pulmonary epithelium and inflammatory signals in acute lung injury: expert review of clinical immunology 2009;5(1):63-75.

10. Hiraiwa K, van Eeden SF. Nature and consequences of the systemic inflammatory response induced by lung inflammation. In: Ong K, editor. Lung inflammation. Rijeka, Croatia: InTech; 2014. doi: $10.5772 / 57392$.

11. Opitz B, van Laak V, Eitel J, Suttorp N. Innate immune recognition in infectious and noninfectious diseases of the lung. Am J Respir Crit Care Med 2010;181(12):1294-1309.

12. Todd DA, John E, Osborn RA. Tracheal damage following conventional and high-frequency ventilation at low and high humidity. Crit Care Med 1991;19(10):1310-1316.

13. Siempos II, Vardakas KZ, Kopterides P, Falagas ME. Impact of passive humidification on clinical outcomes of mechanically ventilated patients: a meta-analysis of randomized controlled trials. Crit Care Med 2007;35(12):2843-2851. 